\title{
Multipurpose soft contact lens care in Japan
}

This article was published in the following Dove Press journal:

Clinical Ophthalmology

17 January 2012

Number of times this article has been viewed

\author{
Hiroshi Toshida ${ }^{1,2}$ \\ Yoshiaki Kadota ${ }^{3}$ \\ Chikako Suto ${ }^{2}$ \\ Toshihiko Ohta' \\ Akira Murakami² \\ 'Juntendo University Shizuoka \\ Hospital, Department of \\ Ophthalmology, Shizuoka, 'Juntendo \\ University School of Medicine, \\ Department of Ophthalmology, \\ Tokyo, ${ }^{3}$ Bausch \& Lomb Japan \\ Co, Ltd, Research and Development, \\ Tokyo, Japan
}

Correspondence: Hiroshi Toshida

Department of Ophthalmology, Juntendo University Shizuoka Hospital,

I 29 Nagaoka, Izunokuni, Shizuoka,

4I0-2295, Japan

Tel $+815594831 \mathrm{II}$

Fax +8I 55948335 I

Email toshida@juntendo.ac.jp
Purpose: To assess the use of multipurpose lens care products via an online survey conducted among soft contact lens (SCL) wearers in Japan.

Methods: The subjects were 1000 men and women aged 15-44 years who reported that they cleaned their SCL by using multipurpose solution at least twice a week. Via the internet, they were asked questions about SCL care, the use of a rubbing step when cleaning SCL, cleaning and replacing lens cases, and recommended SCL care methods.

Results: Of the 1000 SCL wearers enrolled, 94.3\% performed lens care every day lenses were worn, $64.2 \%$ reported rubbing the lenses every time, $57.9 \%$ rubbed the lenses for at least 10 seconds per side, and $64.7 \%$ reported they rubbed the lenses on both sides. Further, $61.2 \%$ reported that they had been given an explanation of SCL cleaning at an eye clinic or contact lens store. Only $49.8 \%$ of subjects reported that they cleaned the lens case every time and $61.7 \%$ replaced the case within 3 months. Only $19.5 \%$ had been given an explanation about lens case care. Half of the subjects reported they had been given no recommendation to use specific SCL care products or could not remember whether or not they had. The most common reason for the recommendation was good compatibility with their type of lens.

Conclusion: More education is needed in Japan regarding methods of SCL care to ensure correct lens cleaning with inclusion of a rubbing step, as well as sufficient cleaning and replacement of the lens case. Of particular interest is the finding that many subjects were not given an explanation about proper SCL care and lens case cleaning and replacement at the time of lens purchase or prescription.

Keywords: soft contact lens, multipurpose solutions, compliance, questionnaire survey, contact lens care

\section{Introduction}

Frequent-replacement soft contact lenses (SCL) and disposable SCL are used worldwide because the incidence of eye disorders is expected to be reduced by the shorter duration of use for each lens. This is also the situation in Japan; however, contrary to expectations, the incidence of eye disorders in Japan has actually increased with the adoption of frequent- and periodic-replacement SCL. ${ }^{1-3}$

Cleaning, disinfection, and rinsing of SCL after wearing are essential to prevent the multiplication of pathogens that can cause infection. ${ }^{4}$ Multipurpose solutions (MPS) are the most popular lens care products, because cleaning, rinsing, disinfection, and storage can be performed with one solution. For example, $86 \%$ of SCL wearers use MPS in Japan. ${ }^{5}$ However, although various MPS products conforming to the specified standards have been approved and released, complications still occur among SCL 
wearers using these solutions. ${ }^{6}$ The purpose of this study was to assess the use of multipurpose contact lens solutions via an online survey of SCL wearers in Japan.

\section{Methods}

The study was conducted in accordance with all International Chamber of Commerce/European Society for Opinion and Marketing Research Code on Market and Social Research rules and all privacy laws. The survey was conducted via the internet in February 2010. The subjects were SCL wearers aged 15-44 years who reported cleaning their contact lenses using MPS at least twice a week. The subjects were randomly selected through a research monitor group contracted with the concerned research agency, and an email was sent directly to their registered email address to confirm qualification status. Only subjects who fulfilled the requirements and agreed to cooperate were allowed to enter the study. Subjects who mainly wore 1-week continuous-wear or daily-replacement soft lenses, who primarily wore or only wore spectacles, or who did not determine their brand of solution or purchase solutions themselves were excluded from the study. Those affiliated with promotional companies, research companies, public relations, mass media, contact lens manufacturers, contact lens retailers, optometrists, and ophthalmologists were also excluded from the study. The subjects were a total of 1000 SCL wearers (400 male and 600 female).

The questions were grouped according to the following topics: (1) frequency of lens care, (2) lens deposits/ cleanliness, (3) inclusion of a rubbing step with cleaning of SCL, (4) cleaning and replacement of the lens case, and
(5) recommendations from an eye care professional about lens care methods. All questions are shown in Tables 2-6.

\section{Results}

\section{Types of lenses and MPS reported by the participants}

The types of lenses consisted of frequent-replacement SCL in $87.6 \%$ of 876 participants, planned-replacement SCL in $9.0 \%$, and conventional SCL in 3.4\%.

The types of MPS consisted of polyhexamethylene biguanide in $73.6 \%$, polidronium chloride in $25.8 \%$, and other MPS or unknown in $0.6 \%$ (Table 1 ).

\section{Frequency of lens care}

When subjects were asked to report the frequency at which they performed contact lens care, the most commonly reported response was "Every day that I wear lenses" which was given by $94.3 \%$ of the subjects. The data regarding frequency of contact lens cleaning are provided in Table 2.

\section{Lens deposits/cleanliness}

When subjects were asked to respond to questions regarding the level of anxiety with regards to lens deposits/cleanliness, $58.5 \%$ were either anxious $(48.9 \%)$ or extremely anxious $(9.6 \%)$ about deposits remaining on the lenses even after routine cleaning. Similarly, 63.4\% (45.2\%, 18.2\% respectively), $65.1 \%$ (42.5\%, $22.6 \%$ respectively), and $63.2 \%$ (42.1\%, 21.1\% respectively) of subjects were either anxious or extremely anxious about deposits on their lenses towards the end of the replacement cycle, eye dryness associated

Table I MPS brands as reported by the $1000 \mathrm{SCL}$ wearers surveyed

\begin{tabular}{|c|c|c|c|}
\hline Brand & Company & $\mathbf{n}$ & $\%$ \\
\hline \multicolumn{2}{|c|}{ Polyhexamethylene biguanide (PHMB) } & 736 & $73.6 \%$ \\
\hline $\mathrm{ReNu}^{\circledR}$ multi-plus & Bausch and Lomb, Rochester, NY & 180 & $18.0 \%$ \\
\hline $\mathrm{ReNu}^{\circledR}$ & Bausch and Lomb, Rochester, NY & 106 & $10.6 \%$ \\
\hline C Cube soft one & Rohto, Osaka, Japan & 132 & $13.2 \%$ \\
\hline Bioclen ${ }^{\circledast}$ one & Ophtecs, Kobe, Japan & 99 & $9.9 \%$ \\
\hline Complete ${ }^{\circledR}$ double moist & AMO, Santa Ana, CA & 91 & $9.1 \%$ \\
\hline Complete $10 \mathrm{~min}^{\circledR}$ & AMO, Santa Ana, CA & 27 & $2.7 \%$ \\
\hline Complete ${ }^{\circledR}$ protect & AMO, Santa Ana, CA & I & $0.1 \%$ \\
\hline Epica $^{\circledR}$ cold & Menicon, Nagoya, Japan & 50 & $5.0 \%$ \\
\hline Comfort care ${ }^{\circledR}$ & CIBA Vision, Atlanta, GA & 21 & $2.1 \%$ \\
\hline FreshLook $^{\circledR}$ care & CIBA Vision, Atlanta, GA & 16 & $1.6 \%$ \\
\hline One Bottle care & Aime, Yokohama, Japan & 13 & $1.3 \%$ \\
\hline \multicolumn{2}{|l|}{ Polidronium chloride } & 258 & $25.8 \%$ \\
\hline Opti-Free $^{\circledR}$ & Alcon, Hünenberg, Switzerland & 187 & $18.7 \%$ \\
\hline Opti Free ${ }^{\circledR}$ plus & Alcon, Hünenberg, Switzerland & 71 & $7.1 \%$ \\
\hline \multicolumn{2}{|l|}{ Other MPS or unknown } & 6 & $0.6 \%$ \\
\hline \multicolumn{2}{|l|}{ Total } & 1000 & $100.0 \%$ \\
\hline
\end{tabular}

Abbreviations: MPS, multipurpose solution; SCL, soft contact lens. 
Table 2 Subject responses regarding frequency of soft contact lens care

\begin{tabular}{lll}
\hline How often do you usually perform lens care? & $\mathbf{n}$ & $\%$ \\
\hline Every day that I wear lenses & 943 & $94.3 \%$ \\
Once every 2-3 days & 46 & $4.6 \%$ \\
Once every 4-5 days & 9 & $0.9 \%$ \\
Once every 6-10 days & $\mathrm{I}$ & $0.1 \%$ \\
Less than once every 10+ days & $\mathrm{I}$ & $0.1 \%$ \\
Total & 1000 & $100.0 \%$ \\
\hline
\end{tabular}

with deposits, and discomfort associated with lens deposits, respectively (Table 3 ).

\section{Cleaning SCL with the inclusion of a rubbing step}

When patients were asked questions regarding whether or not they performed a rubbing step when cleaning their SCL, $64.2 \%$ of the subjects reported doing so every time they clean their lenses (Table 4). Of those who reported rubbing the contact lens during the cleaning process, $57.9 \%$ rub the lens for at least 10 seconds per side. Similarly, 64.7\% of those who reported rubbing the contact lens, reported that they rub the lens on both sides.

When asked from whom they learned to include a rubbing step while cleaning their SCL, $61.2 \%$ of patients reported that they had received an explanation from an eye care professional. Similarly, when asked whether or not they had ever received an explanation or guidance about including a rubbing step while cleaning their contact lenses, $57.1 \%$ of the subjects reported receiving an explanation or guidance by an eye care professional or store assistant. However, $24.4 \%$ reported they had never been instructed to do so and $18.5 \%$ of the subjects could not remember receiving any explanation. Of 379 participants who answered this question (multiple answers), a large proportion (97.1\%) reported that the main explanation that they had been given regarding the purpose of including a rubbing step was to remove deposits from the lens.

\section{Lens cases}

Approximately half of the subjects $(49.8 \%)$ reported that they clean the lens case every time lens care is performed; however, $26.8 \%$ of subjects reported they did not clean the lens case at all (Table 5). Only $19.5 \%$ of subjects reported having received guidance regarding cleaning the lens case, while $49.9 \%$ reported never having received guidance on case cleaning. Similarly, only $17.7 \%$ of subjects reported they had received an explanation or guidance about replacing their lens case, while $52.5 \%$ reported they had never received an explanation or guidance regarding lens case replacement. Although $61.7 \%$ of patients reported replacing their lens case within 3 months (1 month: 12.3\%, 2 months: $23.6 \%$, and 3 months: $25.8 \%$ ), 20.3\% did not change their cases at all. Of those who reported lens case replacement, 69.7\% reported replacing the case when a new case was obtained with the purchase of lens care solutions.

\section{Recommendations about lens care methods}

When asked whether or not specific instructions for use of the MPS or a specific brand of lens care product was recommended, $28.2 \%$ of subjects reported that no suggestion was made; $22.7 \%$ reported receiving a recommendation for both instructions for use and brand (Table 6). Surprisingly, 22.2\% of SCL wearers could not remember whether or not specific instructions for use had been given or a brand recommended. When asked, "What was the reason for the recommendation?" the most common answer was that it was compatible with the subject's current SCL (36.8\%) (multiple answers). Other common answers related to the disinfection efficacy of the product and applicability to other types of SCL.

\section{Discussion}

Contact lens wearers are reported to account for more than $10 \%$ of the Japanese population, ${ }^{3}$ approximately $10 \%$ of whom have been reported to experience problems with their contact lenses, ${ }^{7}$ accounting for $1 \%$ of the total Japanese population. In

Table 3 Subject responses to questions regarding anxiety about lens deposits/cleanliness

\begin{tabular}{|c|c|c|c|c|c|c|c|c|}
\hline & \multicolumn{2}{|c|}{$\begin{array}{l}\text { Deposits left even after } \\
\text { routine cleaning process }\end{array}$} & \multicolumn{2}{|c|}{$\begin{array}{l}\text { Deposits towards the } \\
\text { end of replacement cycle }\end{array}$} & \multicolumn{2}{|c|}{$\begin{array}{l}\text { Eye dryness associated } \\
\text { with deposits }\end{array}$} & \multicolumn{2}{|c|}{$\begin{array}{l}\text { Discomfort associated } \\
\text { with deposits }\end{array}$} \\
\hline & $\mathbf{n}$ & $\%$ & $\mathbf{n}$ & $\%$ & $\mathbf{n}$ & $\%$ & $\mathbf{n}$ & $\%$ \\
\hline Extremely anxious & 96 & $9.6 \%$ & 182 & $18.2 \%$ & 226 & $22.6 \%$ & 211 & $21.1 \%$ \\
\hline Anxious & 489 & $48.9 \%$ & 452 & $45.2 \%$ & 425 & $42.5 \%$ & 421 & $42.1 \%$ \\
\hline Neutral & 176 & $17.6 \%$ & 156 & $15.6 \%$ & 172 & $17.2 \%$ & 180 & $18.0 \%$ \\
\hline Somewhat anxious & 201 & $20.1 \%$ & 176 & $17.6 \%$ & 146 & $14.6 \%$ & 161 & $16.1 \%$ \\
\hline Not at all anxious & 38 & $3.8 \%$ & 34 & $3.4 \%$ & 31 & $3.1 \%$ & 27 & $2.7 \%$ \\
\hline Total & 1000 & $100.0 \%$ & 1000 & $100.0 \%$ & 1000 & $100.0 \%$ & 1000 & $100.0 \%$ \\
\hline
\end{tabular}


Table 4 Subject responses to questions regarding cleaning of contact lenses, specifically related to the inclusion of a digital rubbing step

\begin{tabular}{ll}
\hline Question asked & \\
\hline Response & $\begin{array}{l}\text { Number } \\
\text { (\%) }\end{array}$ \\
\hline
\end{tabular}

\begin{tabular}{ll}
\hline $\begin{array}{l}\text { How often do you usually perform cleaning of your } \\
\text { contact lens by rubbing? }\end{array}$ & \\
Rub every time & $642(64.2 \%)$ \\
Once every 2-3 times & $72(7.2 \%)$ \\
Once every 4-5 times & $12(1.2 \%)$ \\
Once every 6-10 times & $1(0.1 \%)$ \\
Less than the above & $1(0.1 \%)$ \\
Never rub lenses & $272(27.2 \%)$ \\
How did you find out about cleaning & \\
contact lenses by rubbing? & \\
Instructed by eye care professional & $612(61.2 \%)$ \\
Read package inserts & $274(27.4 \%)$ \\
Read cleaning procedures & $15(1.5 \%)$ \\
suggested on manufacturer's homepages & \\
Learned from family/friends & $42(4.2 \%)$ \\
Read pamphlets/lens care instruction & $36(3.6 \%)$ \\
materials placed in clinics & \\
Others & $21(2.1 \%)$
\end{tabular}

Have you ever been given any explanation or guidance about cleaning contact lens by rubbing?

Have been given such an explanation or $\quad 571$ (57.1\%)

guidance by an eye care professional

or store assistant

Have never been guided

$244(24.4 \%)$

Do not remember

$185(18.5 \%)$

What explanation were you given about the purpose

of cleaning SCL by rubbing?

( $n=379$, multiple answers)

Removal of deposits

Removal of bacteria

Avoid reduced vision

$154(40.6 \%)$

Avoid reduced comfort

$52(13.7 \%)$

Avoid trouble with allergies

$73(19.3 \%)$

Prevention of serious eye diseases $\quad$ I27 (33.5\%)

Others

$3(0.8 \%)$

Abbreviation: SCL, soft contact lens.

Japan, the incidence of ocular complications due to contact lens wear has increased markedly, especially since $2007 .{ }^{8}$ This trend is related to an increase in the absolute number of contact lens wearers, ${ }^{8,9}$ however, it is also related to an increase in the number of younger contact lens wearers, a reduction of the price, revision of the Pharmaceutical Affairs Law in Japan in 2005 and the consequent changes in sales methods, noncompliant lens care because of contact lenses being mistaken for disposable lenses, erroneous use of contact lenses, noncompliant lens care, problems with lens case handling and replacement, and failure to undergo periodic examinations.
Among the above-mentioned factors related to the occurrence of complications, noncompliant lens care could be overcome if SCL wearers' awareness of the importance of complete care was improved. ${ }^{10,11}$ According to the present survey, most of the SCL wearers performed lens care, a result that seems to be different from those reported previously. ${ }^{1,2,10,11}$ This is likely a result of the study design as only subjects who stated that they performed lens care at least twice a week were selected for this survey, which resulted in the high percentage of subjects performing lens care every day $(94.2 \%)$.

When purchasing SCL, 57.1\% of the subjects had received an explanation or guidance about including a rubbing step while cleaning their lenses at an eye clinic or CL store. Similarly, this survey found that $64.2 \%$ of the subjects included a rubbing step every time they cleaned their lenses. This is consistent with results reported by Bui et al. ${ }^{11}$ The percentage of SCL wearers who clean their lenses by rubbing is likely to increase if they are given education about proper lens care.

There is considerable room for improvement with respect to the handling of lens cases. Only $49.8 \%$ of the subjects reported that they cleaned their lens case every time the lenses were worn. In addition, $61.6 \%$ of subjects reported that they replaced their case within 3 months of purchase, and $20.3 \%$ did not replace their lens case at all. Furthermore, only $17.7 \%$ of the subjects had received an explanation or guidance about replacing their lens cases.

Previous studies of contact lens wearers have indicated that it is important to educate patients about proper lens care procedures as well as the risk of complications. ${ }^{3,10-12}$ As reported previously, inviting comments from the public and utilizing mass media are effective for this purpose. However, it has also been reported that many contact lens wearers have not incorporated good lens care into practice, although they have learned from educational activities that noncompliant lens care is a risk factor for eye complications. ${ }^{11,13}$ Education regarding proper lens care should be conducted at every patient visit, regardless of whether or not problems are detected. It is also necessary to inform contact lens wearers in advance about the measures that should be taken if any abnormalities occur while wearing lenses.

It is extremely difficult to provide the necessary education or guidance to contact lens wearers who buy lenses on the internet without a doctor's prescription or even consultation with a store assistant. It is likely that the package insert will not always be read in full, if at all. In fact, there is a report that 
Table 5 Subject responses to questions regarding replacement and cleaning of contact lens cases

\begin{tabular}{|c|c|}
\hline \multicolumn{2}{|l|}{ Question asked } \\
\hline Response & Number (\%) \\
\hline \multicolumn{2}{|c|}{ Do you usually clean your lens case? If you answer } \\
\hline \multicolumn{2}{|c|}{ "Yes," then how often do you clean it? } \\
\hline Every time when I do lens care & $498(49.8 \%)$ \\
\hline Once every $2-3$ times of lens care & $108(10.8 \%)$ \\
\hline Once every 4-5 times of lens care & $58(5.8 \%)$ \\
\hline Once every $6-10$ times of lens care & 47 (4.7\%) \\
\hline Less than the above & $21(2.1 \%)$ \\
\hline Never clean lens case & $268(26.8 \%)$ \\
\hline \multicolumn{2}{|l|}{$\begin{array}{l}\text { Have you ever been given an explanation or } \\
\text { guidance about lens case cleaning? }\end{array}$} \\
\hline Have been guided & 195 (19.5\%) \\
\hline Never been guided & 499 (49.9\%) \\
\hline Do not remember & $306(30.6 \%)$ \\
\hline \multicolumn{2}{|c|}{ Have you ever been given an explanation or guidance } \\
\hline \multicolumn{2}{|l|}{ assistant about replacing your lens cases? } \\
\hline Have been guided & 177 (17.7\%) \\
\hline Never been guided & $525(52.5 \%)$ \\
\hline Do not remember & $298(29.8 \%)$ \\
\hline \multicolumn{2}{|c|}{ When do you change your lens case to a new one? } \\
\hline Every month & $123(12.3 \%)$ \\
\hline Every 2 months & $236(23.6 \%)$ \\
\hline Every 3 months & $258(25.8 \%)$ \\
\hline Every 4 months & $37(3.7 \%)$ \\
\hline Every 5 months & $15(1.5 \%)$ \\
\hline Every 6 months & $102(10.2 \%)$ \\
\hline Every $7-12$ months & $22(2.2 \%)$ \\
\hline Every I3-24 months & $4(0.4 \%)$ \\
\hline More than 24 months & $0(0.0 \%)$ \\
\hline No replacement & $203(20.3 \%)$ \\
\hline \multicolumn{2}{|c|}{ When do you replace your lens case with a new one? } \\
\hline Upon obtaining new lens cases upon & 375 (69.7\%) \\
\hline \multicolumn{2}{|l|}{ purchase of lens care solutions } \\
\hline When remarkable stains in lens cases are found & $108(20.1 \%)$ \\
\hline Upon replacement of lenses & $62(11.5 \%)$ \\
\hline When deposits on lenses are annoying & $31(5.8 \%)$ \\
\hline Upon switch to a new bottle of lens care solution & $137(25.5 \%)$ \\
\hline Others & $6(1.1 \%)$ \\
\hline No specific reason & $18(3.3 \%)$ \\
\hline
\end{tabular}

the percentage of contact lens wearers who forget essential items of lens care is 3.8 times higher among those buying lenses on the internet than among traditional buyers. ${ }^{10}$

The present study was based on the results of a survey of soft contact lens wearers, but not on actual ophthalmological examination. Therefore, the results may well be different from the actual incidence of ocular findings and complications. We previously compared ocular findings between SCL wearers with and without inclusion of a rubbing step during cleaning, who performed cold disinfection as lens care, and attended
Table 6 Subject responses to questions regarding recommendations for lens care procedures and products

\begin{tabular}{ll}
\hline $\begin{array}{l}\text { Suggested specific instructions } \\
\text { for use of MPS or brand }\end{array}$ & Number (\%) \\
\hline $\begin{array}{l}\text { Only specific care instructions } \\
\text { were suggested }\end{array}$ & $87(14.2 \%)$ \\
$\begin{array}{l}\text { Both care instructions and brand } \\
\text { were suggested }\end{array}$ & $139(22.7 \%)$ \\
Only brand was suggested & $78(12.7 \%)$ \\
No suggestion & $173(28.2 \%)$ \\
$\begin{array}{l}\text { Do not remember } \\
\text { Reasons for recommendation } \\
\text { (n = 304, multiple answers) }\end{array}$ & $136(22.2 \%)$ \\
It is compatible with your current SCL & \\
$\begin{array}{l}\text { To avoid trouble such as allergies } \\
\text { High disinfection effectiveness }\end{array}$ & $112(36.8 \%)$ \\
Sensitive for your eyes & $31(10.2 \%)$ \\
Usable for any SCL & $74(24.3 \%)$ \\
Others & $62(20.4 \%)$ \\
No reasons provided but & $73(24.0 \%)$ \\
recommendations made & $12(3.9 \%)$ \\
Do not remember & $43(14.1 \%)$ \\
\hline Abbreviations: MPS, multipurpose solution; SCL soft contact &
\end{tabular}

Abbreviations: MPS, multipurpose solution; SCL, soft contact lens.

the outpatient clinic of our hospital for periodic examination. As a result, the percentage of patients with asymptomatic corneal findings such as superficial punctate keratitis and corneal infiltrates was $14 \%$ in the rubbing group, while patients with corneal findings (even though mild) accounted for $50 \%$ of the non-rubbing group. ${ }^{14}$ These results indicate a pitfall in lens care, that is to say performing lens care without the inclusion of a rubbing step might lead to an increased risk of contact lens-related ocular complications. Therefore, attention should be paid to those soft contact lens wearers identified by this survey who did not perform proper lens care. These patients may be at higher risk for early ocular changes that might lead to an increase in the incidence of ocular complications.

In conclusion, this survey on lens care confirmed that soft contact lens wearers know about the importance of proper lens care, but only a small percentage of wearers perform all aspects of lens care, such as cleaning their lenses by including a rubbing step and cleaning and replacing the lens case. Education is important to encourage soft lens wearers to perform better lens care. The best method of education is direct individual guidance by an eye care professional or store assistant at the time of lens purchase or prescription and at all subsequent follow-up visits.

\section{Disclosure}

The authors report no conflict of interest in this work. 


\section{References}

1. Matthews TD, Frazer DG, Minassian DC, Radford CF, Dart JK. Risks of keratitis and patterns of use with disposable contact lenses. Arch Ophthalmol. 1992;110(11):1559-1562.

2. Stapleton F, Dart J, Minassian D. Nonulcerative complications of contact lens wear. Relative risks for different lens types. Arch Ophthalmol. 1992;110(11):1601-1606.

3. Inoue N, Toshida H, Mamada N, Kogure N, Murakami A. Contact lensinduced infectious keratitis in Japan. Eye Contact Lens 2007;33(2): 65-69.

4. Peterson RC, Fonn D, Woods CA, Jones L. Impact of a rub and rinse on solution-induced corneal staining. Optom Vis Sci. 2010;87(12):1030-1036.

5. Morgan PB, Woods CA, Tranoudis IG, et al. International contact lens prescribing in 2010. Contact Lens Spectrum. Special edition; Jan 2011:30-35.

6. Kodama Y. New multipurpose solutions. J Eye [Atarashii Ganka]. 2005;22(10):1345-1348. [Japanese.]

7. Toshida H. Contact lens-related corneal infections; bacterial infections. J Eye [Atarashii Ganka]. 2009:26(9):1193-1198. [Japanese.]

8. Toshida H, Honda R, Iwatake A, et al. Recent trend of infectious corneal ulcer in contact lens wearers needing hospitalization. Jpn J Clin Ophthalmol [Rinsho Ganka]. 2009;63(9):1481-1484. [Japanese.]
9. Toshida H, Suto C. Ocular bacterial infections. In: Higgins J, Traux D, editors. Eye Infections, Blindness and Myopia. New York: Nova Science Publishers; 2009:101-118.

10. Wu Y, Carnt N, Stapleton F. Contact lens user profile, attitudes and level of compliance to lens care. Cont Lens Anterior Eye. 2010;33(4): 183-188. Epub March 15, 2010.

11. Bui TH, Cavanagh HD, Robertson DM. Patient compliance during contact lens wear: perceptions, awareness, and behavior. Eye Contact Lens. 2010;36(6):334-339.

12. Uno T, Fukuda M, Ohashi Y, et al. Survey of severe contact lensassociated microbial keratitis in Japan. J Jpn Ophthalmol Soc [Nihon Ganka Gakkai Zasshi]. 2011;115(2):107-115. [Japanese.]

13. Dumbleton K, Richter D, Woods C, et al. Compliance with contact lens replacement in Canada and the United States. Optom Vis Sci. 2010;87(2):131-139.

14. Murakami A, Toshida H. Handling and care of contact lenses by wearers of disposable contact lenses. J Jpn CL Soc. 2005;47(3):189-192. [Japanese.]

\section{Clinical Ophthalmology}

\section{Publish your work in this journal}

Clinical Ophthalmology is an international, peer-reviewed journal covering all subspecialties within ophthalmology. Key topics include: Optometry; Visual science; Pharmacology and drug therapy in eye diseases; Basic Sciences; Primary and Secondary eye care; Patient Safety and Quality of Care Improvements. This journal is indexed on Submit your manuscript here: http://www.dovepress.com/clinical-ophthalmology-journal

\section{Dovepress}

PubMed Central and CAS, and is the official journal of The Society of Clinical Ophthalmology (SCO). The manuscript management system is completely online and includes a very quick and fair peer-review system, which is all easy to use. Visit http://www.dovepress.com/ testimonials.php to read real quotes from published authors. 